\title{
Identification of antioxidant and antibacterial activities for the bioactive peptides generated from bitter beans (Parkia speciosa) via boiling and fermentation processes
}

\begin{abstract}
The present study reports on the effects of boiling and fermentation processes on the antioxidant activity and antibacterial activity of the peptides generated from bitter beans. The protein content, peptide content, antioxidant activity and antibacterial activity were determined. The peptides were fractionated using size exclusion and the identified using LCMS/MS in combination with PEAKS Studio software. The protein content for raw, boiled and fermented samples was 20,15 and $13 \mathrm{~g} / 100 \mathrm{~g}$ DW and the peptide content was 0.3, 12.1 and $15.1 \mathrm{mg} / \mathrm{g}$ DW, respectively. Fermentation process increased the DPPH activity of bitter beans to $78.48 \pm 3.16 \%$. Fermentation process significantly increased the antibacterial activity of bitter beans towards Escherichia coli (45\%), Salmonella Typhimurium (73\%), Staphylococcus aureus (64\%), and Listeria monocytogenes (57\%). Out of the seven peptides identified in fraction 11, three peptides including EAKPSFYLK, PVNNNAWAYATNFVPGK and AIGIFVKPDTAV demonstrated antibacterial activity at different concentrations $(1000,500$, 250 and $125 \mu \mathrm{g} / \mathrm{mL}$ ). The DPPH activity was only observed for the peptides EAKPSFYLK (74\%) and PVNNNAWAYATNFVPGK (87\%). In conclusion, fermentation process increased the antioxidant and antibacterial activity of bitter beans due to the presence of low molecular weight peptides. The bioactive peptides are very promising ingredients to formulate functional foods and beverages.
\end{abstract}

Keyword: Fermented bitter beans; Bioactive peptides; Food process; Functional ingredients 